\title{
La antropología y el derecho ante los fenómenos posesorios: entre la comunidad y la propiedad ${ }^{1}$
}

\author{
Anthropology and ownership acts: \\ Between community and property
}

\author{
Lidia MONTESINOS LLINARES \\ Doctora en Antropología Social por la Universidad de Barcelona \\ lidiamontesinos@gmail.com
}

Recibido: 5 de enero de 2015

Aceptado: 3 de marzo de 2015

\begin{abstract}
Resumen
La autora hace un repaso de las metodologías de investigación que ponen en relación Antropología y Derecho a partir de su experiencia investigadora en el ámbito de las relaciones de propiedad. La complementariedad entre estas dos disciplinas contribuye ampliamente a la comprensión de conflictos y realidades posesorias complejas — poniendo en relación propiedad y comunidad-, pero no está exenta de tensiones. Como pone de manifiesto la autora, la Antropología jurídica plantea una relación crítica con el Derecho cuando éste muestra intransigencia ante las singularidades antropológicas; cuando pierde de vista que es sólo un medio, una herramienta con fines sociales y antropológicos, y no un fin en sí mismo; o cuando apela recurrentemente a las ficciones jurídicas para legitimarse.
\end{abstract}

Palabras clave: Antropología jurídica; relaciones de propiedad; bienes comunales; derecho; ficción jurídica.

\begin{abstract}
The author reviews the research methodologies that relate Anthropology and Law based in her experience as a researcher in the area of property relations. The complementarity between these two disciplines broadly contributes to the understanding of conflicts and realities of complex ownership-establishing a relationship between property and community-, but is not exempt from tension. As the author shows, Legal Anthropology poses a critical relationship with Law when Legal approaches show intransigence vis-à-vis anthropological peculiarities. Abuse of Legal fictions reveals also a source for Anthropological misunderstandings.
\end{abstract}

Keywords: Legal Anthropology; Property Relations; Commons; Law; Legal Fiction.

${ }^{1}$ La investigación en que se basa este artículo se llevó a cabo con la ayuda de una Beca de Formación del Personal Investigador (BES-2008-002450) del Ministerio de Ciencia e Innovación, inscrita dentro del proyecto de Investigación "Formas de responsabilidad económica y política: entre la formalidad y la informalidad" (SEJ2007-66633) del Grupo de Estudios sobre Reciprocidad (GER) de la Universitat de Barcelona, cuya investigadora principal es Susana Narotzky. 
Referencia normalizada: Montesinos Llinares, L. (2015) La antropología y el derecho ante los fenómenos posesorios: entre la comunidad y la propiedad, en Revista de Antropología Social 24, 53-81.

SUMARIO: 1 . Introducción. 2. La complementariedad entre Antropología y Derecho aplicada a un estudio de caso. 2.1. El estudio normativo: leyes y costumbres. 2.2. Perspectiva procesual: estudio de casos, disputas y conflictos. 2.3. Relaciones de poder y pluralismo jurídico: Hegemonías y antagonismos. 2.4. Genealogía y perspectiva histórica: continuidades, cambios y memorias. 3. Por una definición amplia y no restrictiva del Derecho y la Propiedad. 4. La Antropología jurídica en tensión y relación crítica con la hegemonía del Derecho. 5. Antropología y Derecho: el desvelamiento de las ficciones jurídicas. 6. Referencias bibliográficas.

\section{Introducción}

Las relaciones de confluencia y complementariedad entre Derecho y Antropología son múltiples y variadas tal y como vamos a exponer en este artículo y como demuestra, además, una larga tradición de estudios y reflexiones que se sitúan en la intersección de estos dos saberes. Si ponemos la mirada sobre la Antropología como disciplina, este vínculo aparece muy claramente en los primeros estudios de sociedades tribales, pues algunas de estas investigaciones fueron llevadas a cabo precisamente por juristas y estudiosos del Derecho comparado, quienes insatisfechos con las limitaciones de su propia disciplina — centrada en el estudio de las instituciones jurídicas a partir de modelos y concepciones del Derecho positivo occidental - quisieron ampliar su mirada, cuestionar sus propios conceptos, para comprender los contextos sociales y culturales en los que se desarrollaban las instituciones que querían comprender (Doñate y Romero, 2010; Krotz, 2002)². Así, el interés temprano de la Antropología por las cuestiones jurídicas tiene un vínculo directo con el interés de los estudiosos del Derecho por comprender el contexto social y las formas de vida de sociedades con instituciones jurídicas y formas de regulación diferentes al Derecho positivo moderno y occidental.

Desde los inicios de esta confluencia entre Antropología y Derecho, la delimitación del campo de lo jurídico en los estudios antropológicos ha sido una tarea compleja, debatida y controvertida. Frente a las concepciones normativas de algunos coetáneos, Malinowski (1982[1926]) planteaba ya en sus primeros trabajos una concepción ampliada del derecho y los fenómenos jurídicos:

...el "derecho" y los "fenómenos jurídicos" tal como los hemos descubierto, descrito y definido en una parte de Melanesia, no constituyen instituciones independientes.

${ }^{2}$ Esta inquietud de comprensión de lo jurídico inserto en un campo social ampliado y complejo contribuyó decisivamente al surgimiento de la Antropología Social a mitad del siglo XIX, cuando juristas como H.J.S. Maine, J.J. Bachofen o L.H. Morgan empezaron a observar las reglas de conducta y las costumbres de pueblos que se organizaban en base a normas no escritas. Esta línea de investigación continuó con las aproximaciones holísticas de antropólogos como M. Mauss o B.K. Malinowski, y también con el jurisprudencialismo realista de K.N. Llewellyn (Doñate y Romero, 2010). 
El derecho es más un aspecto de su vida tribal, un aspecto de su estructura, que un sistema independiente, socialmente completo en sí mismo. (Malinowski, 1982:74)

Esta definición antropológica de los fenómenos jurídicos se vincula con el concepto de incrustación — embededness - desarrollado por Polanyi $(2009,2011)$, que en su caso hace referencia a los fenómenos económicos que — como los jurídicosse hallan siempre insertos y en relación con otros aspectos de la vida social e incluyen no sólo leyes y sanciones, sino también relaciones de reciprocidad, intercambio, apoyo mutuo o solidaridad.

En este sentido, el enfoque desde el que he trabajado y a partir del cual propondré algunas reflexiones se enmarca en esta concepción ampliada del derecho y abre la reflexión jurídica a su relación con la economía y la política - siguiendo las propuestas de Chris Hann (1998, 2000) y Benda-Beckmann (1999) para el estudio de las relaciones de propiedad-, y también con el parentesco, la historia y la identidad. Así, veremos cómo el entrecruzamiento de varios enfoques y ámbitos de conocimiento nos permitirá arrojar más luz sobre la realidad social estudiada y también sobre las relaciones no sólo entre Antropología y Derecho, sino también entre los cambios políticos, económicos y jurídicos que van afectando y conformando las formas de vida que estudiamos.

Las reflexiones que plantearé provienen de un trabajo de investigación etnográfica e histórica que he desarrollado en los últimos años y que ha dado forma a mi tesis doctoral ${ }^{3}$, centrada en el estudio de las transformaciones de la propiedad en un pueblo de la montaña navarra, especialmente a través del análisis de los conflictos por el uso, definición y aprovechamiento de determinados recursos comunales - pastos, helechos, leña, madera y agua - Toda experiencia de trabajo de campo etnográfico se desdobla en una reflexión sobre los propios conceptos y supuestos desde los cuales edificamos nuestro quehacer como antropólogas y antropólogos $y$, en este caso, expondré una serie de reflexiones, a partir de mi experiencia de investigación, sobre las distintas formas de relación que se dan entre Antropología y Derecho, contrastando algunos planteamientos epistemológicos propios de la Antropología jurídica.

\section{La complementariedad entre Antropología y Derecho aplicada a un estu- dio de caso}

En el año 2007 plantee mi proyecto de tesis como un estudio de comunidad inspirado en los estudios clásicos - de un pequeño pueblo de la montaña navarra; Goizueta ${ }^{4}$. La voluntad de aprender el habla local — euskera — y realizar una inmer-

${ }^{3}$ La tesis fue dirigida por Ignasi Terradas y defendida el 16 de diciembre de 2013 en la Universidad de Barcelona. Lleva por título "IRALIKU' $K$ : La confrontación de los comunales. Etnografía e historia de las relaciones de propiedad en Goizueta.” y puede consultarse en http:// hdl.handle.net/10803/132603.

${ }^{4}$ Goizueta es un municipio navarro de unos 700 habitantes situado al noroeste de la comunidad foral, muy cerca del límite administrativo con Guipúzcoa. Tiene una superficie de 9.163 hectáreas de las cuales unas 3.650 serían comunales y el resto privadas o patrimoniales. Unas 
sión en la vida local me llevaron a instalarme en el pueblo y acercarme en un primer momento al fenómeno lingüístico y a la identidad vivida de la población, empapándome de sus dinámicas cotidianas, actividades periódicas y celebraciones anuales (Montesinos, 2008). Poco a poco, al ir conociendo mejor el pueblo, situado entre montañas y con una tradición tanto industrial - ferrerías, minas, centrales hidroeléctricas, explotación forestal- como agro-pecuaria, las formas de uso comunal de los recursos y las transformaciones económicas de la vida local empezaron a perfilarse como intereses centrales para el estudio. Al haber constatado también, a través de la documentación del archivo municipal, la existencia en el pueblo de formas de apropiación comunal a lo largo de la historia, su vigencia en el presente y también la persistencia de conflictos y enfrentamientos locales y con las administraciones provinciales respecto a estas formas de apropiación, el interés por las formas de gestión de los bienes comunales desde un enfoque jurídico se fue consolidando.

Comenzaba así, en 2009, una nueva estancia de campo en el pueblo que siguiendo la idea del estudio de comunidad ponía su atención en los conflictos por la posesión y la propiedad de los recursos a partir del estudio jurídico. En este sentido - como he mencionado - las propuestas de Chris Hann (1998, 2000), Benda-Beckmann (1999) o Raúl Márquez (2013) para el estudio de las relaciones de propiedad me sirvieron para enmarcar teóricamente el ámbito de estudio y para poner en relación las transformaciones económicas, políticas y jurídicas que se habían dado en Goizueta respecto al uso y apropiación de los recursos ${ }^{5}$; sin olvidar abordar estos ámbitos desde una perspectiva histórica de larga duración.

La renovación de los estudios sobre bienes comunales y relaciones de propiedad operada por estos autores recupera el concepto antropológico clásico de la propiedad, entendida ésta como relaciones de propiedad: relaciones entre personas respecto a cosas, bienes o recursos; pero también relaciones de reciprocidad y responsabilidad marcadas por la adjudicación de derechos y obligaciones. Las relaciones de propiedad - así como hemos visto para los fenómenos jurídicos - aparecen incrustadas en el orden social y no como un fenómeno separado y estrictamente normativo. La "propiedad" no define la relación entre el individuo y la cosa - como propondría la teoría liberal y de la propiedad privada-, sino que la propiedad debe entenderse, en todo caso, como una relación social o un conjunto de relaciones sociales entre personas respecto a cosas. Esta cuestión - básica en la teoría antropológica clásica (Malinowski 1982[1926]; 1977[1935]; Gluckman 1943, 1955, 1959, 1965, 1969, 1978; Bohannan 1957) - pone en cuestionamiento el concepto mismo de propiedad, fuertemente marcado por el paradigma liberal e individualista, para devolver la mirada a la comunidad, a las relaciones entre las personas y su relación con los recursos, con

1.300 hectáreas se encontrarían en pugna o en litigio entre particulares, vecinos, ayuntamiento y administración foral.

${ }^{5}$ El estudio de la propiedad implica el abordaje de tres ámbitos o esferas estrechamente relacionadas e interconectadas: la esfera del Derecho y la regulación jurídica de la propiedad; la esfera económica en relación al uso de los recursos y su vinculación con la ecología; y la esfera política, donde se organiza y define el orden de gestión de las propiedades y la toma de decisiones. 
los bienes y objetos con los que vive, interactúa y de los que necesita. Es una mirada que enfatiza la dimensión colectiva de la propiedad, pues su ordenamiento afecta a la comunidad en su conjunto y es en su seno que se regula. En esta apertura conceptual se ilumina el carácter político de la propiedad y su estrecha vinculación con las necesidades económicas y sociales de cada colectividad y los recursos y herramientas jurídicas que ésta pone en marcha para su ordenación y reparto.

De esta forma, el enfoque que propone la Antropología jurídica conecta con esta mirada de los estudios sobre las relaciones de propiedad, y es en esta intersección donde se ha situado mi trabajo. Dicho esto, voy a ir desglosando las distintas capas de análisis que han atravesado mi trabajo de investigación que recupera la tradición de los estudios jurídicos en Antropología: el estudio normativo, el análisis de conflictos y procesos de disputa, el ámbito de las relaciones de poder y la perspectiva histórica o genealógica. En estos ámbitos entran en relación la Antropología y el Derecho de forma diversa y podemos desprender de ellos algunas reflexiones respecto a la vigencia y situación de esta tradición epistemológica.

Este recorrido por ciertos aspectos de la metodología y el enfoque epistemológico de la investigación lo haré poniendo como ejemplo ilustrativo el caso del conflicto de los helechales que ha ocupado una parte importante de mi investigación doctoral. Se trata de una disputa que se ha dado en el ámbito local y también en toda la zona de la montaña navarra por la titularidad de ciertos terrenos helechales $-\mathrm{y}$ también castañales - que siendo tradicionalmente terrenos comunales sobre los que los vecinos tenían un derecho de corte y uso del helecho, a través de procesos de particularización, escrituración y registro pasaron a ser reivindicados como privados por parte de muchos vecinos que los habían aprovechado durante años o que los habían adquirido por distintos medios. La reivindicación de un cierto derecho de usucapión, de privatización o de compra se apoya principalmente en la legislación liberal del siglo XIX — las leyes de legitimación de roturas, la Ley Hipotecaria y la creación del Registro de la propiedad - y se enfrenta a la defensa que han hecho tanto la administración navarra como el ayuntamiento y algunos vecinos del pueblo del carácter comunal de los terrenos, basándose en este caso en el Catastro municipal, en el derecho consuetudinario navarro, el carácter imprescriptible de los terrenos comunales - reconocido a partir de la constitución de 1978- y la acusación de usurpación hacia los particulares que reclaman la propiedad privada (Montesinos, 2011).

\subsection{El estudio normativo: leyes y costumbres}

Para la compresión del conflicto de los helechales y también otras disputas por los recursos en Goizueta se hizo necesario desde el principio comprender el marco normativo en el cual se producían, teniendo en cuenta además que en distintas épocas los vecinos habían acudido a instancias mediadoras y a los tribunales para dirimir sus diferencias. Comprender el sistema normativo desde el cual argumentaba cada parte en los juicios, así como los códigos y legislaciones que regulaban el uso y apropiación de estos recursos a lo largo de la historia se aparecía como una cuestión ineludible para entender la complejidad del caso. 
Esta aproximación normativa está estrechamente vinculada a la Historia del Derecho y el Derecho mismo, disciplinas a las que acudí en busca de bibliografía para poder comprender el marco jurídico y legal en el que se insertaba el conflicto de los helechales. Este estudio ha incluido las ordenanzas y regulaciones locales actuales y también las más antiguas, lo que implica comprender las costumbres locales, sus transformaciones a lo largo del tiempo y su codificación en forma de derecho consuetudinario. Implicaba también conocer y constatar la existencia de juicios verbales para la resolución de conflictos locales desde muy antiguo, así como el papel mediador de algunos vecinos, del juez de paz o de la junta vecinal ante las disputas entre vecinos. Por otro lado, frente al estudio de las costumbres locales era necesario conocer la legislación del Reino de Navarra respecto a los bienes comunales y el papel de las Cortes de Navarra y sus representantes en los conflictos por las formas de apropiación en los ámbitos locales, que en Goizueta fue muy importante hasta el siglo XIX y existen diversas sentencias y concordias que resuelven casos de disputas por la propiedad. A partir de la incorporación definitiva de Navarra al Estado español en 1841 - pero ya desde la conquista en 1512 - las leyes comunes del Estado aparecían también como un elemento clave para comprender el conflicto, pues son las leyes del Estado liberal las que permiten en gran medida - o consolidanla particularización y privatización de los terrenos helechales. Aquí cobraba mucha importancia la dimensión política respecto a la negociación y la tensión existente entre la Diputación de Navarra y el Estado español sobre este proceso de adaptación jurídica, un campo específico y controvertido dentro de la Historia del Derecho y la propia historia de Navarra ${ }^{6}$. Finalmente, al acercarnos al presente etnográfico del conflicto irrumpía además otro marco jurídico importante para comprender la deriva de estos terrenos y de las formas de uso de los bienes comunales. Me refiero a la legislación proveniente de la Unión Europea, especialmente la relacionada con la Política Agraria Comunitaria, la conservación medioambiental y la explotación forestal.

El estudio normativo incluye también la comprensión del contexto en el que se crean y modifican las normativas y leyes, especialmente cuando se produce un debate social al respecto. Es el caso, por ejemplo, de la Ley de comunales de 1986 que iba a sustituir al Reglamento para la Administración Municipal de Navarra de 1928, cuya creación y promulgación provocó un importante debate en torno a las formas de uso comunal que interesaba abordar desde una perspectiva antropológica. Así, la labor de juristas y legisladores no queda aislada del contexto social ni reducida a la Exposición de motivos que encabeza una nueva ley, sino que se comprende desde su importancia social o por la necesidad que se tiene de ella.

Este estudio normativo ha permitido reconstruir una historia de transformaciones políticas e institucionales en el territorio navarro de gran importancia para el desarrollo y positivación del derecho consuetudinario de cada zona y para su adaptación

${ }^{6}$ Se hacen lecturas de este proceso en clave colonial - Navarra conquistada por España y sometida a sus leyes-, así como otras que enaltecen la capacidad de adaptación del Derecho navarro al Derecho común sin perder sus características definitorias. 
a las leyes comunes del Estado y de la Unión Europea. Desde la Antropología se ha denominado a este enfoque como paradigma normativo, centrado en el estudio de las normas, leyes, códigos y legislaciones que han ido rigiendo - en este casolas relaciones de propiedad, así como el estudio también del funcionamiento de las instituciones encargadas de promulgar y guarecer estas regulaciones. Este enfoque metodológico, relacionado con un cierto formalismo estatalista o positivismo jurídico fue importante en los inicios de la disciplina antropológica, aunque pronto se produjo una apertura de la mirada hacia los procesos y relaciones sociales que se daban en el seno de los marcos normativos, criticando las visiones formalistas que veían las disputas y conflictos como desviaciones o patologías sociales y entendían las estructuras, las instituciones y las normas como códigos absolutamente coherentes a los que se otorgaba preeminencia sobre los procesos de disputa y resolución de conflictos (Sierra y Chenaut, 2002). En este sentido, en la investigación realizada, más que un enfoque formalista, la atención puesta en las diferentes normativas y legislaciones se hace ya desde una perspectiva plural y compleja — de pluralismo jurídico-, que nos ha permitido poner en relación las formas de vida en Goizueta, las costumbres locales y sus transformaciones con los cambios normativos y legales de las distintas instituciones jurídicas que han interactuado con el ámbito local. No nos hemos reducido al estudio de las leyes del Estado, o de éstas en su tensión con el derecho navarro, sino que se ha abordado el estudio de diferentes sistemas jurídicos - escritos o no escritos - a partir de derechos concretos, privilegios y responsabilidades. Como veremos, es desde esta concepción ampliada del derecho que adquiere profundidad la idea de pluralismo jurídico.

En esta primera capa o ámbito de estudio se pone de manifiesto la confluencia e interrelación entre Derecho y Antropología, y cómo ésta es necesaria para entender un conflicto concreto y su desarrollo. El estudio normativo es importante, en general, para comprender conflictos que se dan entre ley y costumbre - también entre hechos y derechos-, y para el estudio de las relaciones de propiedad es especialmente relevante dada la importancia que adquiere la documentación legal y las sentencias judiciales en los procesos de disputa. La Antropología suele quedar corta en fuentes para el estudio jurídico y para adoptar una perspectiva histórica y esto es algo que tanto la documentación jurídica como la Historia del Derecho pueden subsanar.

\subsection{Perspectiva procesual: estudio de casos, disputas y conflictos}

Como bien expusieron Sierra y Chenaut (2002) en un interesante artículo sobre las corrientes dentro de la Antropología jurídica anglosajona, después de los años 50 se dio un cambio de orientación tanto en la Antropología jurídica como en la Antropología política desde el estudio normativo hacia el estudio de los procesos e interacciones sociales; un giro epistemológico que se consolidó en los años 70. Tomaron preeminencia entonces los estudios de caso extensos sobre procesos de disputa y formas de resolución de conflictos, entendiendo éstos no como desviaciones sino como procesos sociales cotidianos. Así, se empezó a estudiar el Derecho en prácticas sociales y culturalmente situadas, posando la mirada más sobre los litigantes que sobre los jueces o legislaciones; sobre los argumentos de cada parte y cómo 
se manejaban y resolvían los conflictos, y si efectivamente se conseguían restaurar una cierta armonía social. Estos enfoques entienden que los procesos jurídicos son parte de la vida social y que el Derecho no es un sistema independiente de la sociedad o la cultura, sino que ésta se expresa a través de él.

De alguna forma, el análisis de los procesos y las redes sociales está más vinculado a la Antropología que al Derecho, pues como decía se centra más en las condiciones particulares de grupos e individuos que en las regularidades estructurales o en las normativas, dando preeminencia a lo singular, a lo situado, frente a la universalización del Derecho. Se considera así que las personas construyen el derecho a partir de estos procesos de conflicto, así como construyen sistemas de obligaciones, prestaciones mutuas y redes de reciprocidad que son también costumbres jurídicas. El desfase entre el ideal de la norma y las prácticas de los sujetos constituye un campo de análisis propiamente etnográfico, basado en el estudio de los usos concretos y las relaciones de hecho. En el caso de las relaciones de propiedad son muchos los autores que han resaltado la importancia de analizar las prácticas y usos concretos en relación a los ideales y normativas (Malinowski, 1977[1935]; Herskovits, 1952; Benda-Beckmann, 1999; Márquez, 2013); por ejemplo, observar etnográficamente si quien utiliza realmente un terreno es el propietario reconocido legalmente; si no es así qué tipo de cesión se produce y en función de qué reglas o acuerdos; qué se argumenta en los conflictos ante la administración y cuáles son los motivos reales para reclamar un terreno; qué usos se declaran y cuáles son escondidos, etc. La variedad de casos y situaciones es muy amplia y sólo puede comprenderse sobre el terreno, mediante el trabajo etnográfico, pues no queda reflejada en los registros ni en la documentación jurídica.

Esta perspectiva hace hincapié en las estrategias concretas de los sujetos y su capacidad - agency - para generar normas y regulaciones propias al margen o en tensión con las normativas consuetudinarias, oficiales o estatales. No obstante, como la Antropología jurídica ha ido reflexionando, ni todo son estrategias concretas, ni todo es estructura y normatividad, si no que se deben integrar ambas perspectivas para comprender esa relación sistémica entre reglas y procesos, entre acciones individuales y experiencias sociales en un contexto normativo o con costumbres instituidas, pues ambas esferas coexisten y se construyen mutuamente (Sierra y Chenaut 2002).

Siguiendo esta tradición epistemológica, la investigación desarrollada ha tratado precisamente de integrar estas perspectivas, poniendo en relación el estudio normativo con la realidad local y los conflictos concretos que allí se disputaban. Al entrar a un análisis de este tipo para el caso del conflicto de los helechales lo que las sentencias denominaban "usurpación del comunal" podía entenderse en un marco histórico de larga duración, en el que se producen grandes transformaciones en la economía local con la aparición de las plantaciones de arbolado que llevan a al cierre de muchos terrenos; o cambios políticos también de gran relevancia, como es la desarticulación de la gestión comunal y el proceso de municipalización de los bienes comunales (cf. Lana Berasain, 2004; Ortega Santos, 2002, 2001). Al indagar en los procesos concretos vemos también qué vecinos son los que reclaman usos particulares del comunal y en función de qué intereses, así como podemos analizar 
en qué leyes apoyan sus demandas y con qué estrategias particularizan el comunal. Además, es interesante ver cómo la disputa va evolucionando a lo largo de las décadas y cómo los cambios legislativos que se van sucediendo — cambios en los criterios de resolución del conflicto - han provocado grandes tensiones. Los saltos generacionales también tienen una relevancia destacada en el caso, pues son las generaciones más jóvenes las que han reivindicado el comunal frente a sus mayores que quisieron particularizarlo en un momento en que la tradición comunal en la que se criaron empezaba a resquebrajarse. Es adentrándonos en estos detalles que los ideales de justicia e igualdad aparecen en el centro de la disputa, tensionando los intereses particulares con los comunes, y es entonces cuándo el conflicto deja de ser una disputa por la titularidad de unos terrenos - como se presenta en los casos judiciales - y pasa a ser una pugna entre generaciones, entre concepciones distintas de la justicia y de cómo adaptarse y reordenar las posesiones en un contexto nuevo.

El estudio de las disputas aparece así, como es propio de la Antropología jurídica, en el centro de la investigación, pues es a partir de su comprensión y análisis que podemos desprender las ideas de justicia que chocan o conviven en el lugar de estudio, las distintas concepciones y usos que se confrontan. Como vamos a ver enseguida, a este enfoque habrá que sumar una constatación importante que da paso a una comprensión más amplia y compleja: el hecho de que siempre existe una jerarquía normativa, una visión que tiene más peso que otras en cada momento y, por lo tanto, debemos tener en cuenta no sólo la confrontación de intereses, sino también las relaciones de poder y hegemonía que se dan en todo proceso social.

\subsection{Relaciones de poder y pluralismo jurídico: Hegemonías y antagonismos}

Siguiendo nuevamente a Sierra y Chenaut (2002) llegamos a los años 80, momento en que se incorporan con fuerza las perspectivas de la dominación y el cambio social, es decir: cómo el poder y las transformaciones sociales inciden en los procesos jurídicos. Esto significa incidir nuevamente en que el Derecho no es un sistema de normas homogéneo y cerrado creado por un grupo de expertos, sino que es producto de la agencia humana; pero además, se enfatiza que éste es ventajoso para unos a expensas de otros. El Derecho no es imparcial y los cambios jurídicos condensan relaciones sociales de poder. Las normas son construcciones sociales que van cambiando según las circunstancias y los contextos históricos de poder y dominación, siendo el resultado de discusiones, argumentaciones y negociaciones entre actores conscientes. El Derecho aparece así como un código abierto, como un lenguaje a disputar marcado por las relaciones de poder y la historicidad de los procesos sociales, en constante transformación y recreación.

Esta perspectiva reaccionaba críticamente contra ciertas visiones armónicas del Derecho que había planteado el estructural-funcionalismo, apostando por una perspectiva dinámica, de corta y larga duración, atenta a lo micro y macro de los procesos y poniendo el énfasis en las relaciones de poder (Foucault 2001[1981]), de hegemonía (Gramsci, 1986), dominación/resistencia y antagonismos (Laclau y Mouffe, 1987). Este enfoque epistemológico que trabajaron muchos otros autores permite reforzar una perspectiva materialista crítica que de cuenta de las 
desigualdades económicas y de poder intrínsecas a los procesos productivos, y por lo tanto, propietarios. De hecho, la perspectiva marxista es clave para comprender las relaciones de propiedad como relaciones de poder y dominación, y el caso del conflicto de los helechales no es ajeno a los procesos de acumulación primitiva, desigualdades económicas y acaparamiento de tierras como los que Marx analizó en El Capital (1974[1867]). La "tragedia de los registros" — como la he denominado- se inicia cuando un grupo de vecinos acaudalados, alfabetizados y con relaciones con Madrid y los órganos de poder deciden registrar — amparados por las legislaciones liberales - terrenos que hasta entonces usufructuaban y que eran considerados comunales. No fueron los vecinos arrendatarios los que abanderaron este proceso, ni mucho menos los trabajadores sin tierras que, de hecho, se vieron afectados por el cierre de terrenos. Son principalmente los grandes propietarios, comerciantes y familias señoriales las que proceden a registrar las tierras, partiendo así el conflicto de una situación de desigualdad que marcará su desarrollo, las formas de afrontarlo y las consecuencias de su resolución

En la investigación desarrollada se ha procurado ir dibujando el campo de fuerzas que ha mantenido vivo el conflicto en cada época y hasta la actualidad, dando cuenta de las relaciones de antagonismo que ponían en tensión las relaciones de propiedad, los intereses en juego y las economías morales o concepciones de la justicia que se confrontaban, pues éstas se han ido modificando con el paso de las décadas poniéndose además en relación con procesos más amplios y luchas de fuerzas en el campo político e institucional - como puede ser el enfrentamiento entre carlistas y liberales a lo largo del siglo XIX, el paso de Reino independiente a gobierno foral, la efervescencia de los años 30 en la península, el contexto de la guerra civil y la posguerra, los años del desarrollismo, la llamada transición a la democracia o la entrada en la Unión Europea-. El conflicto de los helechales se extiende a lo largo de más de un siglo - así como otros conflictos por la posesión y la propiedad tienen una procedencia inmemorial - pero la composición de fuerzas enfrentadas y las relaciones de poder a lo largo del tiempo han ido cambiando: vecinos contra señoríos y órdenes religiosas en la Edad Media; vecinos labriegos frente a dueños de mayorazgos, caciques o "jauntxos" a lo largo del siglo XX; administración local aliada o en tensión con la administración provincial; el gobierno navarro en tensión con el Estado; oposición de intereses entre pastores y empresas forestales; tensión entre las prácticas locales y las normativas europeas; entre otras confrontaciones de intereses, cosmovisiones (Frigolé, 2012), concepciones y valores. Para entender el conflicto en cada momento y en su desarrollo general es imprescindible comprender las distintas relaciones de fuerza y de poder y el contexto en el que se alían distintos actores e intereses que más adelante pueden estar de nuevo enfrentados.

En este sentido, es interesante constatar cómo la defensa de los terrenos helechales particularizados desde la segunda mitad del siglo XX la encabezan quienes más terrenos acapararon por su situación de privilegio en décadas anteriores y también los grandes empresarios forestales y comerciantes que adquirieron tierras a partir de los años 50, siendo todos ellos considerados "jauntxos" - denominación despectiva hacia los "señoritos"- por los defensores del comunal. Frente a ellos se 
situará la Diputación de Navarra, defensora del derecho consuetudinario de carácter comunal y en abierta oposición a las leyes liberales del Estado. Pero más interesante es ver cómo una gran mayoría de vecinos que adquirieron terrenos helechales al poder acceder a la compra de una casa en esa misma época - tras décadas de arrendamiento - se sumarán a la defensa de esas tierras privatizadas aprovechando el interés y la lucha que abanderaban los grandes propietarios, revelándose en contra de la costumbre para estos casos aunque manteniendo la defensa del derecho comunal de pasto y otras costumbres comunales para otros efectos; manteniendo viva la confrontación con la Diputación de Navarra durante décadas. No será hasta los años 70 y 80, con la llegada a los ayuntamientos de nuevas generaciones — desligadas generalmente de la vida del caserío y empapadas de las luchas políticas e ideológicas de la época - que la defensa del carácter comunal de los terrenos cobre de nuevo importancia en el pueblo y se trate de revertir la "usurpación" aunando fuerzas con el Gobierno de Navarra, incluso aunque éste haya tenido distinto color político por no decir opuesto - al que ha imperado históricamente en Goizueta - el nacionalismo vasco- . A la confrontación directa con los "jauntxos" los defensores del comunal tendrán que sumar el enfrentamiento con sus propios familiares por terrenos pequeños y sin apenas valor económico pero que a fuerza del uso y la defensa de los mismos fueron adquiriendo un valor sentimental e identitario considerable, además de ser un posible seguro de vida ante la decadencia de la economía agro-pecuaria.

Como vemos, las relaciones de antagonismo y de fuerza son complejas y se encuentran inmersas además, para el caso estudiado, en una disputa jurídica y política entre la hegemonía del Estado y las leyes liberales y la hegemonía del gobierno navarro en defensa de sus derechos históricos. En el ámbito local, las distintas generaciones y sus grupos de poder también se disputan la construcción de un relato coherente sobre el conflicto, el poder de decisión para su resolución y la influencia sobre la mayoría de vecinos. Nuevamente, Derecho y Antropología colaboran para comprender en profundidad la historia y las relaciones posesorias en un caso concreto.

De esta forma, aunque la Antropología jurídica ha privilegiado el estudio de las regulaciones consuetudinarias y no estatales, en muchos casos se impone una mirada sobre el papel del Derecho estatal y su influencia en las prácticas cotidianas, pues es su carácter hegemónico e impositivo el que provoca conflictos o dificulta su resolución a nivel local. Las relaciones de antagonismo están lejos de configurar un panorama de confrontación democrática o espacio de diálogo, pues en ellas cristalizan las relaciones de poder. En este sentido, podemos considerar que esta perspectiva es contra-hegemónica porque constata la existencia de una lucha de fuerzas desigual y constante, enfatizando el carácter político de los conflictos y poniendo al mismo nivel - en sentido epistemológico - a los distintos actores sociales, los valores que defienden, sus necesidades y argumentos, en lugar de reducir la mirada a un enfrentamiento entre la ley del Estado y el derecho consuetudinario, o el derecho instituido y quienes lo incumplen o se resisten a él. El valor contra-hegemónico de poner en pie de igualdad las distintas posiciones enfrentadas no significa que éstas se igualen de facto o que se confunda la legalidad y la legitimidad de los distintos 
planteamientos, sino que se trata de una operación de legitimación de las distintas concepciones jurídicas en disputa como parte de un ejercicio real y consecuente de abordar el pluralismo jurídico.

En esta línea, en los años 90 y desde distintas disciplinas se ha enfatizado el hecho de que el Derecho no es sólo un instrumento de dominación - como había planteado el marxismo-, sino que puede ser también una herramienta de resistencia. No es sólo tampoco un instrumento para garantizar libertades como formuló el liberalismo - reconocimiento de derechos civiles y la igualdad de oportunidadessino que los subordinados o excluidos de estos derechos fundamentales también pueden servirse de él y de su carácter productivo - tal y como planteó Gramsci (1986) en su propuesta en torno a la hegemonía y la resistencia-. El Derecho es un referente central en la legitimación de saberes y poderes para garantizar un determinado consenso, pero también para mostrar cómo se confrontan los poderes y se genera la resistencia, pues el Derecho expresa una correlación de fuerzas, una relación social y no un estado de cosas. Los conflictos y disputas como el de los helechales son espacios de performance y de producción cultural que van definiendo el devenir de los sistemas jurídicos. De hecho, en el caso de los helechales es muy visible este carácter productivo de los conflictos, pues es a partir de los juicios y confrontaciones legales por estos terrenos que se crean y desarrollan muchos aspectos de las leyes sobre usos, aprovechamientos y apropiaciones del comunal; se legisla a partir del conflicto existente y es a través de los juicios emprendidos por algunos vecinos que se va generando una jurisprudencia que permite posicionar un criterio legal. Así, yendo más allá del concepto de pluralismo jurídico que parece mantener aislados los distintos sistemas o cuerpos normativos, se crean conceptos como el de interlegalidad (Sousa Santos, 1987; 1995) o el de campo social semi-autónomo (Moore, 1973) para nombrar la pluralidad y complejidad de las interacciones e influencias recíprocas entre distintos cuerpos normativos o instituciones jurídicas, entendiendo que la hibridación y los propios conflictos son los que van a definir cada momento y cada espacio de confrontación.

Desde estas concepciones, la confluencia entre Derecho y Antropología aparece de nuevo como necesaria y enriquecedora, pues permite poner en relación los distintos sistemas jurídicos que se influyen y construyen mutuamente en función de las jerarquías que hay dentro de esa pluralidad de órdenes.

\subsection{Genealogía y perspectiva histórica: continuidades, cambios y memorias}

En este punto, y como hemos ido perfilando ya, se hace necesario remarcar la importancia de una mirada histórica para comprender tanto los fenómenos jurídicos como las relaciones de propiedad y los conflictos de intereses. Incluso aunque nos centremos en comprender una determinada disputa en un momento concreto o en el presente etnográfico al que nos aproximamos, el pasado, la memoria, la historia de las transformaciones vividas aparece siempre como un factor influyente y en muchas ocasiones determinante para comprender los conflictos actuales, pues las ideas respecto a la justicia y las formas de vida y organización tienen generalmente un anclaje temporal ineludible. 
En el caso estudiado, la perspectiva de larga duración histórica nos pone en relación a toda una serie de cambios y transformaciones marcadas por avatares políticos, guerras de conquista, luchas por la emancipación y relaciones de dominación que han ido definiendo las relaciones de propiedad como una herencia entre generaciones. A una escala más local o regional, la perspectiva histórica nos permite reconstruir dilatadas pugnas entre familias; disputas entre derechos de uso y derechos reales y señoriales que conforman relaciones de servidumbre y explotación; desigualdades económicas y enfrentamientos políticos arraigados en personajes y familias concretas y prácticas que se asientan en derechos inmemoriales. Así, la contextualización socio-política y socio-económica no sólo de los cambios normativos e institucionales sino también de los conflictos y disputas por el territorio arroja gran cantidad de luz sobre el trasfondo social y antropológico de las relaciones de propiedad y nos da claves también para comprender las dinámicas de cambio, las formas de operar de las instituciones jurídicas y la capacidad de actuación de los actores locales. La perspectiva histórica permite profundizar en lo que mencionaba al inicio: la conjunción de los ámbitos político, jurídico y económico; la incrustación de los fenómenos jurídicos y posesorios en el orden social; y en una forma de comprender el derecho como un fenómeno social indesligable de un contexto histórico concreto.

En el caso de las relaciones de propiedad la perspectiva histórica es imprescindible para comprender sus transformaciones, y es especialmente interesante adoptarla si hay documentación jurídica para reconstruirlas. En el estudio desarrollado se hace un uso muy importante de documentación jurídica antigua y contemporánea seleccionada del archivo municipal y del juzgado de paz que se interpreta y analiza a partir del conocimiento etnográfico de la realidad local, a partir de entrevistas con los actores implicados, de sus opiniones y relatos sobre los conflictos que aparecen reflejados en la documentación. Esta labor de poner en diálogo la documentación del archivo y la realidad presente y vivida por los vecinos del pueblo permite poner en relación los casos jurídicos, las sentencias y las leyes respecto a cada caso con la realidad material y el contexto en que se desarrollaron, una tarea en la que vuelve a ser de máxima utilidad la bibliografía sobre Historia del Derecho.

De alguna forma, a mayor profundidad histórica mayor variabilidad y factores de análisis aparecen, abriendo la posibilidad de una perspectiva comparativa dentro del mismo contexto de estudio para distintas épocas. En el caso estudiado, además, los usos comunales tienen una procedencia inmemorial que aparece destacada en la documentación jurídica y que también tienen muy en cuenta los propios vecinos del pueblo, cuestión que empuja la mirada etnográfica constantemente hacia tiempos pasados, tratando de reconstruir una historia de transformaciones.

Para este viaje hacia el pasado — que en muchos casos se asocia a la pregunta por los orígenes del comunal y su sentido primigenio- es interesante apoyarse en el método genealógico que propuso Foucault (1971), pues éste plantea el devenir histórico como una concatenación de invenciones azarosas fruto de las relaciones de poder, que lejos de evidenciar una historia lineal, evolutiva o necesaria enfatiza precisamente la importancia de las relaciones y los conflictos en el devenir histórico, entendiendo lo social como un campo de fuerzas en pugna. Desde esta perspectiva, 
en el trabajo realizado se analizan varias emergencias históricas o momentos de inflexión como fueron el auge del liberalismo en el siglo XIX o la industrialización, y también la procedencia - frente a la idea de origen - de los bienes comunales, es decir, cómo los derechos de uso y apropiación fueron conformando un marco jurídico que a través de las confrontaciones históricas fue configurando los bienes comunales modernos. Estas procedencias, incluidos también los relatos míticos y utópicos, han ido marcando las transformaciones del comunal y las concepciones que tenemos de ellos en nuestra contemporaneidad.

En este sentido, la importancia de la perspectiva histórica se vislumbra también en los argumentos jurídicos y en las apelaciones ideológicas a ciertos valores del pasado asociados con la vida campesina, con una economía de subsistencia familiar y con formas de vida no capitalistas que se han ido reinventando y reformulando a lo largo del tiempo, siendo parte ya de una memoria histórica y política que va ligada en Navarra a su derecho consuetudinario, pero también a la historia reciente de luchas políticas y grandes transformaciones económicas. El papel de la memoria política del comunal en relación especialmente con la guerra civil y las desigualdades de clase ha sido determinante en la forma de abordar el conflicto de los helechales en el presente.

Por otra parte, debemos destacar también que el paso del tiempo y la temporalidad de la vida humana aparecen como un trascendental fáctico imprescindible para comprender las transformaciones de las formas de apropiación y los mecanismos de re-ordenación de las mismas a lo largo de generaciones y periodos históricos (Márquez, 2013; Montesinos, 2013). El paso del tiempo y los cambios históricos van modificando y alterando estas relaciones de forma inexorable, y éstas se van re-estructurando mediante distintas formas de transmisión de la propiedad o de re-ordenación de los bienes comunes; motivo por el cual las he calificado como relaciones fluctuantes, cambiantes, cuya ordenación no puede ser nunca definitiva (Montesinos, 2013).

De la misma manera, la dimensión fáctica del tiempo convierte a éste en un elemento de legitimación de la apropiación de los recursos en distintas concepciones jurídicas - la tierra para quien la trabaja y quien invierte su tiempo en ella, derechos temporales de uso, usucapión...- - y un elemento que define y regula las formas de apropiación en la mayoría de sistemas jurídicos - calendario de usos, prescripción de derechos por desuso en el tiempo, derechos de antigüedad o vecindad, etc.- - (cf. Márquez 2013). En definitiva, la perspectiva histórica y la atención sobre la temporalidad de las relaciones constituyen una perspectiva ineludible para la comprensión de las relaciones de propiedad.

\section{Por una definición amplia y no restrictiva del Derecho y la Propiedad}

Hasta aquí he tratado de mostrar cómo ha sido necesaria la comunicación entre la Antropología y el Derecho para la comprensión de los fenómenos posesorios en un contexto concreto. El conflicto de los helechales no se comprende si reducimos la mirada a la documentación jurídica — sentencias, títulos de propiedad, catastro-, es más, ésta nos puede resultar ambigua e incluso arbitraria si comparamos 
documentos de distintas épocas. Las fuentes que nos proporciona el Derecho no nos dan una explicación de lo que sucede y por qué sucede, y si lo hacen, es sólo de forma unilateral, desde la visión legal. En este sentido, el estudio etnográfico permite comprender los casos concretos y la complejidad en la que se desenvuelve el conflicto, donde se entremezclan factores que el Derecho no capta: transformaciones económicas y del mundo rural, diferencias de clase y estatus entre los implicados en el conflicto, diferencias en la extensión de tierras acaparadas, etc. Lo cual no quiere decir que para conseguir una comprensión profunda de esta larga disputa no necesitemos acudir a las fuentes documentales que provienen del Derecho - documentación jurídica y análisis legislativo y judicial en torno al caso- para comprender también la legalidad a la que apelan los litigantes. La etnografía necesita nutrirse también con estas fuentes.

Considero que al constatar esta interdependencia entre el Derecho y la Antropología a la hora de abordar los conflictos sociales, abogamos por una concepción ampliada del Derecho - incluyendo un concepto ampliado de costumbre - y también de la Propiedad que se asientan en la tradición antropológica, pues no reducimos los casos judiciales a meros ejercicios doctrinarios sino que tratamos de comprender el contexto social en el que se desarrollan y sus implicaciones, recuperando la idea de la función o finalidad social tanto del Derecho como de la Propiedad. Desde este punto de vista, la Antropología jurídica elabora una metodología de investigación y comprensión de los fenómenos jurídicos que podría contribuir en la mediación o resolución de los mismos cuando el Derecho no consigue coadyuvar en una resolución pacífica y pactada de los problemas que acontecen en la sociedad. La mirada antropológica persigue una comprensión profunda de los conflictos cuya resolución no pasa por resolver una problemática legal o un proceso judicial, sino por restaurar una cierta armonía social, por conseguir un cierto consenso sobre cómo solucionar de forma justa una confrontación de intereses o un cambio en las formas de vida y organización.

Esta definición amplia y no restrictiva del Derecho y de la Propiedad que permite una comprensión compleja de los conflictos implica como hemos visto retomar la perspectiva relacional y no esencial de ambos conceptos, incorporando además el factor de interacción, imbricación e interlegalidad que se produce por la convivencia de diferentes sistemas codificados y consuetudinarios que se influencian mutuamente ${ }^{7}$. Los sistemas legales, así como las concepciones de la justicia no son fenómenos aislados y específicos sino que se hayan interconectados, superpuestos, interpenetrados y mezclados en nuestras mentes y en nuestras acciones. Esto queda muy claro en el conflicto de los helechales, cuando vemos como las personas acuden a legislaciones y argumentos distintos según los intereses en juego o incluso por experimentar contradicciones en sus propias concepciones de la justicia. En este

${ }^{7}$ Como expuse en otro lugar, entiendo por regímenes consuetudinarios aquellos ordenamientos protagonizados por algunos sectores de la sociedad que no se corresponden totalmente con el derecho oficializado, englobando tanto los sistemas con una larga trayectoria histórica - fuentes del derecho del Estado-, como aquellos otros en absoluto reconocidos por éste (Márquez, Montesinos y Sarkis 2011: 172). 
punto, debemos tener en cuenta que la pluralidad de concepciones de la justicia y sentidos comunes pueden convivir en un mismo grupo doméstico o incluso en un mismo individuo respecto a cuestiones distintas, y que en este sentido, el concepto de pluralismo jurídico se amplia hasta abarcar las distintas concepciones que pugnan dentro de un mismo contexto o sistema jurídico.

La aparente disolución, desde esta perspectiva, de un objeto de estudio concreto y delimitado para el análisis jurídico (bien sean las normativas, los juicios, la resolución de conflictos, etc.), lejos de abocarnos a un cierto relativismo o vaciamiento de significados, nos permite justamente visualizar el carácter indefinido, complejo, contradictorio y fluctuante de las relaciones jurídicas y de propiedad, núcleo teórico sobre el que gira la reflexión que he propuesto en mi investigación (retomando y profundizando lo que formulara Marx, 1983[1867]; Malinowski, 1977[1935]; o Grossi 1992[1988]; entre otros; Montesinos, 2013). Esto pone en evidencia la parcialidad y el carácter siempre relacional tanto de las leyes y normativas como de las instituciones jurídicas, mostrando así el carácter eminentemente político de su existencia, escapando de fundamentos teológicos o trascendentales con los que suelen legitimarse las instituciones del Derecho positivo, así como la necesidad de comprender su inmanencia, a veces arbitrariedad, para insistir en la necesidad de flexibilizarlas y adaptarlas a los cambios que experimentan nuestras sociedades y para enfrentar los conflictos que se producen (Supiot, 2007). La posibilidad que arroja este enfoque de comprender las distintas concepciones de la justicia que se ponen en relación ante un problema concreto permite tener una visión amplia y compleja de la problemática jurídica sin caer en reduccionismos positivistas, evolucionismos coloniales, paternalismos estatalistas o autoritarismos en nombre de una justicia superior o universalista. Poner en pie de igualdad distintas concepciones de la justicia es poner en pie de igualdad ambas disciplinas: Derecho y Antropología; es "...tomar en consideración la función antropológica de las leyes humanas, es decir, reconocer el sitio del derecho dentro de la construcción de las identidades individuales y colectivas." (Supiot, 2007: 124)

De alguna forma, las visiones legalistas o positivistas del Derecho y de la Propiedad han contribuido a difuminar esta función antropológica del Derecho y de la Propiedad, así como han pretendido borrar las relaciones de poder o la historicidad de todo proceso social. En el conflicto de los helechales esta pérdida de perspectiva ha reducido un conflicto histórico, político y económico a disputas judiciales individuales por la titularidad de ciertos terrenos; disputas provocadas además por las contradicciones entre unos códigos y leyes — los del Estado - y otros — el derecho consuetudinario y el derecho navarro-. Esto nos permite visualizar cómo los medios creados para ordenar, regular y definir la propiedad - como el Registro de la Propiedad, por ejemplo - se sitúan en ocasiones por encima de los fines sociales de las relaciones de propiedad; los medios triunfan sobre los fines, que serían en este caso repartir y ordenar de una forma justa los derechos de uso y apropiación de los recursos. El olvido de esta función social de los recursos, de la importancia de este fin colectivo para la convivencia y la regulación de la sociedad no hace más que entorpecer la resolución de las disputas y evadir el trasfondo político que tienen las 
confrontaciones por la propiedad, que son al fin y al cabo, las que permiten definir una idea de justicia común en orden a fines compartidos.

El profundo error y el irrealismo básico de los juristas que creen realista eliminar las consideraciones sobre justicia en el análisis del derecho consiste en olvidar que el hombre es un ser bidimensional, cuya vida social se desarrolla a la vez en el terreno del ser y en el del deber-ser. [...] La obra jurídica responde a la necesidad, vital para cualquier sociedad, de compartir un mismo deber ser que la prevenga de la guerra civil.

[...] Se trata de una técnica porque su sentido no está encerrado en la letra de un texto sagrado inmutable, sino que procede, como en cualquier objeto técnico, de fines que le son dados desde afuera por el hombre, fines humanos y no divinos. [...] Por lo tanto, resulta igualmente falso reducirlo, como se tiende a hacer actualmente, a una "pura técnica" vacía de significación, que remitirlo, como se hacía antes, a las reglas consideradas inmutables de un supuesto Derecho natural, puesto que en ambos casos se pierde lo esencial, que es la capacidad del derecho para someter a la razón las formas más diversas de ejercicio del poder político o de la potencia técnica. (Supiot, 2007: 25-26; 31-32)

\section{La Antropología jurídica en tensión y relación crítica con la hegemonía del Derecho}

Si bien a lo largo del estudio realizado y también de los casos que se presentan en este monográfico podemos ver que existe una relación de ida y vuelta entre el Derecho y la Antropología; una relación de mutuo conocimiento entre ambas disciplinas en la que juristas y legisladores recurren al conocimiento antropológico a la hora de generar leyes o implantar reformas, así como la Antropología recurre al Derecho para profundizar en su conocimiento de las realidades locales; también se pueden ver algunas tensiones, contradicciones y malinterpretaciones tanto del Derecho sobre la Antropología como viceversa (Assier-Andrieu, 1999). En este sentido, aunque nuestra apuesta epistemológica sitúa ambas disciplinas en pie de igualdad, lo cierto es que en el estudio de las relaciones de propiedad el Derecho, y el derecho de propiedad privada especialmente, tienen un carácter dominante y hegemónico respecto a la visión ampliada que acabamos de exponer que implica poner la mirada sobre la comunidad y los derechos colectivos. Esta hegemonía se expresa claramente en el conflicto de los helechales y especialmente en la forma de afrontar su resolución, pues a pesar de la fuerte presión ejercida por el Gobierno de Navarra en defensa del carácter comunal de los terrenos - amparado por un derecho histórico reconocido-, la solución adoptada ha sido repartir los terrenos en conflicto entre los particulares y el común, reconociendo cierta legitimidad —o debiéramos decir legalidad - a las inscripciones en el registro y las privatizaciones. La preeminencia de la propiedad privada y de las titularidades individuales en la economía capitalista se vislumbra también en la férrea defensa que los vecinos han hecho de sus apropiaciones individuales, yendo en contra de costumbres inmemoriales y de su propio gobierno autonómico. Aunque no es regla general, la actitud de algunos vecinos responde a lo que MacPherson (1979) llamó individualismo posesivo. 
Así, aunque desde múltiples campos del saber, el paradigma liberal de la propiedad individual absoluta ha sido puesto en cuestión y debatido (desde la historia para el Estado español vs. Congost, 2000; Congost y Lana, 2007; Serna Vallejo, 2011) y desde la Antropología se ha llamado la atención sobre la convivencia, tensión y complementariedad entre las formas de uso y apropiación particular, comunal, pública, e infinidad de variantes, en contra de la idealización y perfección de la propiedad privada (Hann, 1998, 2000), no obstante, la individualización de las relaciones de propiedad y de la adjudicación de derechos sigue conformando de forma genérica nuestra forma de entender el Derecho y la Propiedad. Nuestro Derecho positivo y la legislación de los Estados liberales siguen teniendo como puntal básico la defensa y legitimación de la propiedad privada y los derechos individuales, construyendo así un Derecho individualizador, un Derecho que separa en lugar de unir, que genera — en términos de Durkheim (1985[1893]) — una solidaridad negativa:

Lo que caracteriza a los derechos reales es que, por sí solos, dan nacimiento a un derecho de preferencia y de persecución de la cosa. En ese caso, el derecho que tengo sobre la cosa es exclusivo frente a cualquier otro que viniere a establecerse después del mío. [...] Ahora bien, para que así suceda, es preciso que el lazo jurídico una directamente, y sin mediación de otra persona, esta cosa determinada y mi personalidad jurídica. [...] En rigor, se puede ejercer un derecho real creyéndose solo en el mundo, haciendo abstracción de los demás hombres. Por consiguiente, como sólo por intermedio de las personas es por donde las cosas se integran en la sociedad, la solidaridad que resulta de esta integración es por completo negativa. No hace que las voluntades se muevan hacia fines comunes, sino tan sólo que las cosas graviten con orden en torno a las voluntades. [...] Una solidaridad tal no hace con los elementos que relaciona un todo capaz de obrar con unidad; no contribuye en nada a la unidad del cuerpo social. (Durkheim, 1985[1893]: 136-137)

Frente a esta concepción de lo social, la Antropología jurídica privilegia el estudio de las costumbres e instituciones comunales, de las relaciones de reciprocidad, apoyo mutuo y parentesco (cf. Douglass, 2003[1970], 1977; Contreras, 1996). El Derecho, estudiado de esta forma, es un Derecho que une, que es social, y que genera una solidaridad - digamos - positiva. Así, a la idea de comunidad o sociedad que se auto-regula y provee de sus propias normas - las que puede cambiar y modificar según sus necesidades y anhelos-, se impone la idea del Derecho como propiedad individual, aislada de su contexto social, abstracta en su definición y aplicación y que instaura una separación artificial entre los sujetos de derecho. Mientras la Antropología persigue la comprensión de la comunidad, de su forma de organización e interacción hacia dentro y hacia afuera, el Derecho positivo se empeña en aislar al individuo con sus derechos del conjunto de la sociedad, operando así un proceso de separación que deja al sujeto solo y desamparado en manos de las instituciones. Es muy clara la explicación que desarrolló Durkheim sobre las formas de solidaridad que genera la apropiación individual:

Si el poseedor de cada derecho pudiera siempre ejercitarlo sin traspasar jamás los límites, permaneciendo cada uno en su sitio, no habría lugar a comercio jurídico 
alguno. Pero, de hecho, sucede continuamente que esos diferentes derechos están de tal modo empotrados unos en otros, que no es posible hacer que uno se valorice sin cometer una usurpación sobre los que lo limitan. [...] Son, pues, necesarias relaciones para reparar el perjuicio, si está consumado, o para impedirlo; pero no tienen nada de positivo. No hacen concurrir a las personas que ponen en contacto; no implican cooperación alguna; simplemente restauran o mantienen, dentro de las nuevas condiciones producidas, esta solidaridad negativa cuyo funcionamiento ha venido a perturbar las circunstancias. Lejos de unir, no han hecho más que separar bien lo que está unido por la fuerza de las cosas, para restablecer los límites violados y volver a colocar a cada uno en su esfera propia. [...] En resumen, las reglas relativas a los derechos reales y a las relaciones personales que con ocasión de los mismos se establecen, forman un sistema definido que tiene por función, no el ligar unas a otras las diferentes partes de la sociedad, sino por el contrario, diferenciarlas, señalar netamente las barreras que las separan. No corresponden pues, a un lazo social positivo; la misma expresión de solidaridad negativa de que nos hemos servido no es perfectamente exacta. No es una verdadera solidaridad, con una existencia propia y una naturaleza especial, sino más bien el lado negativo de toda especie de solidaridad. [...] En efecto, los derechos de los individuos, tanto sobre ellos mismos como sobre las cosas, no pueden determinarse sino gracias a compromisos y a concesiones mutuas, pues todo lo que se concede a los unos necesariamente lo abandonan los otros. (Durkheim, 1985[1893]: 139-141)

Vemos aquí reflejadas, en las palabras de Durkheim, las ideas que manifestara también Proudhon (1983[1840]) respecto a la propiedad y que inciden en esta oposición radical entre comunidad y propiedad:

La propiedad es el derecho que tiene el hombre de disponer de la manera más absoluta de una propiedad social. Por consiguiente, si estamos asociados para la libertad, la igualdad y la seguridad, no lo estamos para la propiedad; luego, si la propiedad es un derecho natural, este derecho natural no es social. Propiedad y sociedad son conceptos que se rechazan recíprocamente: es tan difícil asociarlos como unir dos imanes por sus polos semejantes. Por eso, o la sociedad mata a la propiedad o ésta a aquélla. (Proudhon, 1983[1840]: 59)

Ante esta contradicción o situación indeseable de ruptura de la comunidad las corrientes marxistas, socialistas y anarquistas abogaron de distinta forma por los derechos de uso por encima de las apropiaciones privadas:

La ocupación no sólo conduce a la igualdad, sino que impide la propiedad. [...] la ocupación está siempre subordinada a la población [...] Todo ocupante es, pues, necesariamente poseedor o usufructuario, calidad que excluye la de propietario. [...] el usufructuario está bajo la inspección de la sociedad y sometido a la condición del trabajo y a la ley de igualdad. [...] El hombre recibe el usufructo de manos de la sociedad, que es la única en poseer de un modo permanente: el individuo pasa, la sociedad nunca muere. (Proudhon, 1983: 82)

Gluckman $(1943,1969,1978)$ —en quien hemos basado nuestra explicación inicial - también incide en esta idea del uso y de las relaciones de propiedad como 
un elemento clave para la cohesión y conformación del orden social, cuestión que encontramos también en otras etnografías de sociedades tribales (Herskovits, 1952; Bohannan, 1957) y que marcan por ello la definición antropológica de la propiedad como relaciones de propiedad:

La posesión no puede ser absoluta porque lo más importante en la propiedad es el papel que juega en el vínculo de las relaciones concretas. [...] La ley de propiedad en la sociedad tribal no define tanto los derechos de las personas sobre las cosas cuanto las obligaciones debidas entre personas con respecto a las cosas. [...] De esta manera, las personas no sólo crean su cultura material y se vinculan a ella, sino que van creando por medio de ella sus relaciones... (Gluckman, 1978: 66-67)

Por su parte, Alain Supiot (2007), desde una perspectiva más contemporánea, también enfatiza la dimensión colectiva o necesariamente común a la que debe abocarse el Derecho:

Otros juristas no niegan que el derecho tenga algo que ver con la justicia, pero sólo para identificarla en seguida con la maximización de las utilidades individuales. Según esta perspectiva sólo hay derechos individuales. Toda regla es convertida en derechos subjetivos: [...]. Se distribuyen derechos como si se repartieran armas, y después que gane el mejor. Así desgranado en derechos individuales, el Derecho desaparece como bien común. Porque el derecho tiene dos caras, una subjetiva y la otra objetiva, y son dos caras de una misma moneda. Para que cada cual pueda gozar de sus derechos, es preciso que esos derecho minúsculos se inscriban en un derecho mayúsculo, es decir, un marco común y reconocido por todos. (Supiot, 2007: 27-28)

La Antropología en la medida en que hace emerger los casos particulares y las relaciones entre las personas en un contexto determinado problematiza la generalización e individualización que opera el Derecho para transformarse en ley. Las contradicciones y tensiones entre estas visiones deben situarse en un plano de igualdad y de diálogo para tratar de abordar un enfrentamiento que no puede resolverse en la abstracción jurídica y normativa, sino en el seno de las relaciones sociales. Nuevamente se ilumina el carácter político de las relaciones de propiedad y su dimensión colectiva, algo que empieza a despuntar y a reconocerse incluso legal y constitucionalmente en algunos países como derechos colectivos o culturales, o mediante el derecho a la participación en la creación jurídica y en la resolución de conflictos (Aparicio, 2013).

El repaso que hemos hecho a las perspectivas de la Antropología jurídica nos permite visualizar esta subdisciplina como un enfoque crítico con las visiones más dogmáticas e intransigentes del Derecho positivo y el formalismo estatal, que no toman en consideración el pluralismo jurídico, el carácter social de las regulaciones jurídicas, las relaciones históricas de poder o cualquier elemento ético que quede fuera de los propios reglamentos jurídicos. En este sentido, la Antropología jurídica tendría mucho más que dialogar y compartir con las escuelas de Derecho comparado y realista, con la Sociología del Derecho o con los juristas interesados en lo que 
Eugen Ehrlich $(2005$ [1903, 1906]) denominó el Derecho vivido. Es en diálogo con estas escuelas y tradiciones que podemos situar a la Antropología y al Derecho en pie de igualdad, en su voluntad de comprensión de los conflictos y las vías de resolución de los mismos o para la comprensión de las ideas de justicia que imperan en un contexto determinado. Poca igualdad podemos vislumbrar entre el positivismo legalista y la Antropología, o entre ésta y los organismos inter y transnacionales que imponen su ley sin responder a ninguna clase de mandato social o soberanía democrática.

Vemos así cómo las distintas formas de relación entre Antropología y Derecho nos permiten problematizar las concepciones más conservadoras o positivistas del Derecho, que son las que históricamente se han convertido en hegemónicas. Pero insistimos en que ambas perspectivas están imbricadas para comprender realidades locales y sus conflictos en torno a la posesión y la propiedad: hace falta siempre el Derecho, comprender lo individual, pero también hace falta siempre comprender la comunidad, las relaciones entre sus miembros. Este diálogo constante, y esta tensión epistemológica sirven para contrarrestar cierta intransigencia del Derecho frente a las singularidades antropológicas, frente a las excepciones a la norma y los conflictos, pues en ocasiones - lo hemos visto en el caso de los helechales - tanto abogados como juristas denotan una cierta arrogancia y superioridad al creerse en posesión de una verdad trascendente, cayendo en descalificaciones hacia los sujetos que se sirven del orden jurídico formal por un ansia "irracional" de justicia, por desconocimiento o sin dominar su lenguaje (Costa, 2003[1901]).

Al plantear esta tensión, desde la Antropología - como saber menor-, comparecen otras concepciones provenientes del Derecho como el pluralismo jurídico o la interlegalidad, concepciones que son contra-hegemónicas en la medida que otorgan una importancia epistémica a las visiones locales y las ponen al mismo nivel que el saber que emana del Derecho y del Estado. De este modo aparecen las visiones alternativas que emergen desde el Derecho y que al ser receptivas a las complejidades que ofrece la Antropología como saber inmerso en la concreción de lo local, aportan más elementos para la resolución de conflictos. Esto permite establecer una relación de mayor contenido y profundidad con la realidad social fortaleciendo el vínculo de la institución del Derecho con el acto de impartir justicia. Para enfatizar esta relación de complementariedad e interdependencia cobra importancia y sentido retomar la tradición de los estudios antropológicos y jurídicos clásicos, profundizando en ellos, ahondando en sus planteamientos y conceptos, para reivindicar un saber que por haber sido relegado no ha perdido su vigencia.

\section{Antropología y Derecho: el desvelamiento de las ficciones jurídicas}

Para terminar, quisiera apuntar una última reflexión respecto a las posibilidades y potencialidades que abre el diálogo entre la Antropología y el Derecho. Me refiero - como ya he dicho - a la capacidad de este diálogo para contribuir y aportar en la consecución de un Derecho más justo y adaptado a las necesidades sociales de un contexto concreto, pero también para la reflexión y desvelamiento de las ficciones jurídicas y el carácter ficcional con el que suele operar el Derecho. 
Henry Maine, en El Derecho Antiguo (1977[1893]), estudió el derecho primitivo y cómo éste acababa incorporándose en un código, finalizando así su desarrollo espontáneo. Con la aparición de los códigos, según Maine, los cambios e innovaciones en el Derecho ya no surgían espontáneamente - como en los sistemas consuetudinarios- sino que partían de un deseo consciente de progreso o de abarcar nuevos aspectos de la vida social. Este deseo de mejorar las instituciones civiles mediante la modificación del derecho escrito es lo que caracterizaría a las sociedades progresivas (como la nuestra) y las diferencia de las estacionarias, que permanecerían sin cambios.

Aunque esta interpretación adolece del reduccionismo evolucionista de la época y no deja ver que el trasfondo de la investigación de Maine pone más interés en desentrañar las formas del derecho primitivo que en enaltecer el Derecho positivo occidental (aunque lo haga), lo que nos interesa es retomar la pregunta por las formas en que se modifica el Derecho codificado, para dar así una vuelta más a las reflexiones planteadas desde nuestro presente. Según Maine, el deseo de cambio y progreso en materia de derecho viene precedido por una necesidad social, por las exigencias de la opinión pública, y existen tres formas para realizar estos cambios: las ficciones legales ${ }^{8}$,

${ }^{8}$ El concepto de ficción jurídica hace referencia a una estrategia para cambiar el Derecho que reinterpreta la ley sin cambiarla realmente. Es utilizado por Maine para designar toda afirmación con que se oculta o trata de ocultar la alteración hecha en una regla del derecho, cuya aplicación cambia, pero cuyo texto subsiste (Maine 1893: 29). Las ficciones legales tienen la ventaja de que innovan sin que se note, transformando el sistema de derecho ocultando la transformación. De alguna forma, la ficción jurídica instrumentaliza el poder judicial para modificar el derecho sin cambiar las leyes, sin alterar en absoluto el texto de la jurisprudencia. Así, los cambios no se advierten aunque sean claros y violentos; parece que las reglas y las leyes se hayan vuelto más elásticas, pero en realidad lo que pasa es que han cambiado aunque se mantenga la ficción de que no lo han hecho. Assier-Andrieu ha considerado que "La ficción legal es una herramienta del pensamiento jurídico que sirve para estrechar el abismo continuamente excavado entre las necesidades sociales y el orden del derecho" (Assier-Andrieu, 1996: 56), afirmando así que algunas ficciones jurídicas son vitales para la organización en profundidad de la sociedad (1996: 58). Maine también consideraba que las ficciones legales eran procedimientos útiles para cambiar un derecho rígido ante un deseo de mejorar; ya que al ocultar el cambio no provocaban recelos entre el sector más conservador. No obstante, la eficacia y legitimidad de las ficciones legales en casos concretos no quería decir que éstas debieran instalarse permanentemente en el Derecho, pues su papel como impulsoras del desarrollo histórico del derecho debía entenderse y tolerarse solamente en el contexto de un estado infantil del desarrollo social, aspirando cualquier sistema de jurisprudencia a borrar las ficciones jurídicas y a utilizar la legislación como el medio más honesto de cambiar el Derecho: resulta indigno de nosotros buscar un efecto de utilidad reconocida por medio tan grosero como una ficción legal (Maine, 1893: 30). Las ficciones legales hacen más difícil comprender y ordenar la ley, dificultan la clasificación de las leyes, pues la regla del derecho se convierte sólo en una pauta, en la cáscara, dentro de la cual se albergan las antiguas y las nuevas interpretaciones escondidas bajo la misma máscara. Este es un inconveniente desde el punto de vista jurídico, pero hay que contar también con el aspecto moral: la grosería que supone manejar el derecho a voluntad. 
las consideraciones de equidad ${ }^{9}$ y la legislación ${ }^{10}$, que se darían precisamente en un orden evolutivo.

Las necesidades sociales y la opinión pública van siempre delante del derecho. [...] El derecho es estable y las sociedades de que nosotros hablamos progresan; el más ó el menos del bienestar de los individuos que las componen depende de la prontitud con que el derecho se aproxima a la opinión. (Maine, 1893: 28)

Maine consideraba así que la opinión pública era el motor que promovía cambios en el interior del Derecho, pero ¿qué en qué consiste este motor de cambio que es la opinión pública en nuestro presente? Hemos visto a lo largo del texto que esta exigencia social no es un todo homogéneo que defienda a una sola voz el camino que debe seguirse, sino que es precisamente un campo de fuerzas e intereses, una confrontación política en la cual el Derecho juega un papel fundamental en la legitimación de esos cambios y en la materialización de los mismos. Las convenciones normativas proceden de una ficción de consenso que instituye verdades que posteriormente adoptan formas jurídicas, y en este sentido, las ficciones jurídicas son las operaciones constituyentes que fundan el Derecho como tal. En estas maniobras, el Derecho se desdobla como objeto y herramienta de los cambios, difuminando su rol instrumental en una operación que tiene como prioridad la autolegitimación del Derecho por encima del objetivo de impartir justicia.

En el conflicto de los helechales - por volver a nuestro ejemplo- el jurista defensor del carácter comunal de los terrenos recurre a la Historia de Navarra, a la etnografía y al conocimiento de la costumbre para argumentar en los juicios. Sin embargo, hemos detectado que incurre en una ficción jurídica, pues para justificar la defensa del comunal apela a la costumbre inmemorial de aprovechamiento del helecho cuando esta costumbre ya está en desuso, ha perdido su razón de ser, y lo

${ }^{9}$ Las consideraciones de equidad son un punto medio entre las ficciones legales y la legislación, se refieren a un cuerpo cualquiera de reglas, existentes al lado del derecho civil, fundadas en principios distintos, y pretendiendo en cada caso particular sobreponerse á ese derecho, en virtud de una pureza superior atribuida á sus principios (Maine, 1893: 30). En este caso, la modificación que se introduce en el derecho proviene de una consideración de equidad, de una idea de justicia patente y alegable que se basa en la concepción de unos principios más sagrados que el Derecho y que pueden, por tanto, aplicarse sin necesidad de una autoridad competente. En el conflicto de los helechales hemos podido ver cómo operaba una consideración de equidad a la hora de establecer los convenios transaccionales entre particulares y ayuntamiento para repartirse las superficies en conflicto. Se ha otorgado un porcentaje menor de tierras a aquellos vecinos que tienen grandes superficies de tierra en conflicto, y un porcentaje mayor a los vecinos que tenían pocas hectáreas en conflicto, estableciendo así un mecanismo de reparto que disminuye las desigualdades y tiende a equiparar las superficies que finalmente conseguirá cada particular (cf. Montesinos, 2011; 2013).

${ }^{10}$ La legislación sería para Maine el estado intelectual más avanzado para producir cambios en el Derecho, pues lo mejora y perfecciona a partir de un poder, de una autoridad o asamblea parlamentaria que se supone es el órgano de la sociedad entera. En este caso, la autoridad para el cambio emana de una persona o de una corporación constituida o de los poderes del magistrado. Los legisladores tienen el poder de imponer las obligaciones que convengan en cada caso a los miembros de la comunidad; eso sí, tal y como dice Maine, limitados por la opinión pública. 
que se plantea precisamente en este conflicto es su transformación, pues la reivindicación de los vecinos es que el cambio en la costumbre sea reconocido y se de legitimidad a los registros y la usucapión. En este caso, la ficción jurídica consiste en defender los bienes comunales apelando a una costumbre que ya no se practica, haciendo como si ese orden comunal y el derecho consuetudinario todavía existieran y estuvieran vigentes.

El diálogo entre Derecho y Antropología permite desvelar estas ficciones y operar —en términos de Foucault (2001) — una ruptura de evidencias: cuando parece que hay que resolver quién ostenta la titularidad de los terrenos, el conocimiento en profundidad del problema nos muestra que lo que en realidad se debate es cuál debe ser el nuevo estatuto de los bienes comunales en nuestro presente, con los usos actuales y la configuración actual de la sociedad. Así, la perspectiva ampliada y multisituada que hemos ido describiendo permite identificar y desvelar las ficciones jurídicas; estas operaciones de enmascaramiento de las problemáticas sociales bajo el velo de problemas estrictamente legales o judiciales, aportando no sólo en la resolución de los mismos, sino también en la creación de un marco jurídico renovado adaptado a las necesidades y contingencias sociales.

La aportación que Derecho y Antropología pueden hacer a la resolución de conflictos situándose en pie de igualdad y manteniendo un diálogo abierto, parte de la concepción ampliada expuesta, que implica promover una escucha activa de las diferentes reivindicaciones de justicia que se dan respecto a un mismo problema, de las justificaciones y argumentos de cada parte en su defensa, aceptando el conflicto, la negociación, el derecho de rebelión ante la ley injusta, y la participación de los actores implicados en pie de igualdad (cf. Aparicio, 2013). Como hemos argumentado ya, los conflictos y la confrontación de intereses y concepciones de la justicia son fundamentales en la creación del Derecho, algo que desde Maine, se resisten a considerar ciertas corrientes ideológicas: "Uno de los aspectos más preocupantes de la ideología de la gobernación es que no le otorga lugar alguno a los conflictos y a la acción colectiva de los hombres en la marcha de las sociedades. Se vincula así con la utopía totalitaria de un mundo libre de conflictos sociales." (Supiot, 2007: 256)

Para la resolución pacífica de los problemas planteados es necesario un estudio pormenorizado de cada caso y su relación con el caso en general, del contexto socio-económico y las implicaciones del conflicto en el futuro de ese contexto, especialmente ante momentos de cambio o transición, donde es imprescindible la participación de todos los actores implicados directa e indirectamente otorgándoles un grado de autonomía en la toma de decisiones:

La superioridad del Estado providencial sobre los Estados totalitarios no radicó en efecto en el otorgamiento de protecciones sociales (a menudo menos ambiciosas y más precarias que las de los Estados fascistas o comunistas), sino en la garantía de los derechos de acción colectiva que autorizan a los dominados a poner frente a los dominantes su propia concepción de un orden justo. Los sindicatos, la huelga, la negociación colectiva, se volvieron piezas de una maquinaria institucional que transforma relaciones de fuerza en relaciones de derecho. (Supiot, 2007: 219) 
Así como los inicios de la Antropología se vinculan con el trabajo de algunos juristas que querían conocer mejor las sociedades para poder legislar con conocimiento de causa, la relación de complementariedad entre Derecho y Antropología puede contribuir a la consecución de una sociedad más justa; con una legislación adaptada a la cambiante realidad social y sus necesidades, con mecanismos de mediación y resolución de conflictos que atiendan a las problemáticas sociales y no sólo a la dogmática jurídica. El Derecho debe tener en cuenta la vida de las personas sobre las cuales precipita su fuerza y los procesos históricos de transformación para que este ingreso del Derecho en la vida no acontezca como una relación vertical. La Antropologia puede aportar la imagen de unos sujetos que en su vida cotidiana y en la forma de gestión y resolución de sus conflictos no están capturados de antemano por un Derecho positivo o instituido a partir de un pacto social. La apertura a esta relación de mutua confluencia entre Derecho y Antropología brinda la posibilidad de pensar de otra forma las relaciones entre vida y Derecho, o entre Derecho y sociedad.

\section{Referencias bibliográficas}

APARICIO, Marco.

2013 "Ciudadanías intensas. Alcances de la refundación democrática en las constituciones de Ecuador y Bolivia" en VV.AA. Crisis de la democracia y nuevas formas de participación, Valencia: Tirant lo Blanch, pp. 237-264.

ASSIER-ANDRIEU, Louis.

1996 Le droit dans les sociétés humaines. Paris: Nathan.1999 “L'anthropologie, entre la négation et l'imitation du droit. Contribution à une approche pluridisciplinaire des politiques normatives." La juridicisation du politique. Leçons scientifiques, Paris, LGDJ, Recherches et travaux du RED\&S à la maison des Sciences de l'Homme, vol. 7.

BENDA-BECKMANN, Franz von; BENDA-BECKMANN, Keebet von.

1999 “A Functional Analysis of Property Rights, with Special Reference to Indonesia” en Toon van Meijl y Franz von Benda-Beckmann (Eds.) Property rights and Economic Development. Land and natural resources in Southeast Asia and Oceania. London: Kegan Paul International, pp. 15-56.

BOHANNAN, Paul.

1957 Justice and judgment among the Tiv. London: Oxford University Press for the International African Institute.

CONGOST, Rosa.

2000 "Sagrada propiedad imperfecta. Otra visión de la revolución liberal española." Historia Agraria revista de agricultura e historia rural, no 20, Abril 2000, pp. 61-93.

CONGOST, Rosa; LANA, José Miguel (Eds.).

2007 Campos cerrados, debates abiertos. Análisis histórico y propiedad de la tierra en Europa (siglos XVI-XIX). Pamplona: Universidad Pública de Navarra. 
CONTRERAS, Jesús (Coord.).

1996 Reciprocidad, cooperación y organización comunal: desde Costa a nuestros días. Zaragoza: Instituto Aragonés de Antropología y Federación de Asociaciones de Antropología del Estado Español.

COSTA, Joaquín.

2003 [1901] "El problema de la ignorancia del derecho y sus relaciones: el status individual, el referéndum y la costumbre.” Biblioteca Virtual Universal. Madrid.

DOÑATE, Miguel; ROMERO, Pablo.

2010 “Bibliografía. Antropología jurídica” Revista d'Etnologia de Catalunya no 35, pp. 257-264.

DOUGLASS, William Anthony.

1977 Echalar y Murélaga: oportunidad y éxodo rural en dos aldeas vascas. San Sebastián: Auñamendi Argitalgaria; 2 vol. 2003 [1970] Muerte en Murélaga: el contexto de la muerte en el País Vasco. Barcelona: Barral Editores S.A.

DURKHEIM, Émile.

1985 [1893] La División del trabajo social. 2 vol. Barcelona: Planeta-De Agostini.

EHRLICH, Eugen.

2005 [1903, 1906] Escritos sobre Sociología y Jurisprudencia. Madrid: Marcel Pons.

FOUCAULT, Michel.

2001 [1981] Un diálogo sobre el poder y otras conversaciones. Madrid: Alianza Editorial.1971 Nietzsche, la genealogia, la historia. Madrid: La Piqueta.

FRIGOLÉ, Joan.

2012 “Cosmologías, patrimonialización y eco-símbolos en el Pirineo catalán en un contexto global” en Revista de Antropología Social no 21, pp. 173-196.

GLUCKMAN, Max.

1943 "Essays on Lozi land and royal property." Bodes-Livingstone Paper No. 10. Livingstone: The Bodes-Livingstone Institute.

1955 The judicial process among the Barotse of Northern Rhodesia. Manchester: Manchester University Press for the Rhoda-Livingstone Institute.

1959 The Technical Vocabulary of Barotse Jurisprudence. American Anthropologist, Volume 61, Issue 5, pp. 743-759. doi: 10.1525/aa.1959.61.5.02a00020

1965 The Ideas in Barotse Jurisprudence. New Haven and London: Yale University Press.

1978 Política, derecho y ritual en la sociedad tribal. Madrid: Akal. 1969 "Property Rights and Status in African Traditional Law", en Max Gluckman (Ed.), Ideas and Procedures in African Customary Law. London: Oxford University Press, 252-265.

GRAMSCI, Antonio.

1986 Cuadernos de la cárcel. Vol. 1. México: Ediciones Era. 
GROSSI, Paolo.

1992 [1988] La propiedad y las propiedades. Un análisis histórico. Madrid: Editorial

HANN, Chris. Civitas S.A.

1998 "Introduction: the embeddedness of property" en Chris Hann (Ed.): Property relations. Renewing the anthropological tradition. Canterbury: Cambridge University Press.

2000 "The Tragedy of the Privates? Postsocialist Property Relations in Anthropological Perspective." Max Planck Institute for Social Anthropology Working Papers, Halle /Saale.

HERSKOVITS, Melville.

1952 "Property" en Melville Herskovits: Economic Anthropology. The Economic Life of Primitive Peoples. New York: Norton Library, pp. 311-392.

KROTZ, Esteban (Ed.).

2002 Antropología jurídica: perspectivas socioculturales en el estudio del derecho. Barcelona: Anthropos.

LACLAU, Ernesto; MOUFFE, Chantal.

1987 Hegemonía y estrategia socialista. Hacia una radicalización de la democracia. Madrid: Siglo XXI.

LANA BERASAIN, José Miguel.

2004 "La desamortización foral (1841-1861)" en FEDHAV (Fundación para el Estudio del Derecho Histórico y Autonómico de Vasconia): Iura Vasconiae $\mathrm{n}^{\circ} 1$. Revista de Derecho Histórico y Autonómico de Vasconia, Donostia, pp. 437-452.

MACPHERSON, Crawford Brough.

1979 [1962] La teoría política del individualismo posesivo. De Hobbes a Locke. Barcelona: Editorial Fontanella.

MAINE, Henry.

1893 El derecho antiguo considerado en sus relaciones con la historia de la sociedad primitiva y con las ideas modernas. Madrid: Escuela tipográfica del Hospicio.

MALINOWSKI, Bronislaw.

1977 [1935] El cultivo de la tierra y los ritos agrícolas en las Islas Trobriand. Los jardines de coral y su magia. Barcelona: Labor.

1982 [1926] Crimen y costumbre en la sociedad salvaje. Barcelona: Ariel.

MÁRQUEZ, Raúl; MONTESINOS, Lidia; SARKIS, Diana.

2011 "Ordenando la Propiedad: tres estudios de caso sobre regímenes consuetudinarios y regulación estatal.” Revista de Antropología Social, Vol. 20, pp. 171-201. Disponible en: http://www.redalyc.org/pdf/838/83821273007.pdf

MÁRQUEZ, Raúl.

2013 Construir la propiedad. Las formas y usos del derecho en una ocupación de Salvador de Bahía. Santiago de Compostela: Andavira. 
ORTEGA SANTOS, Antonio.

2002 La tragedia de los cerramientos. Desarticulación de la comunalidad en la provincia de Granada. Valencia: Centro Francisco Tomás y Valiente UNED AlziraValencia. Fundación Instituto de Historia Social.2001 "La desarticulación de la propiedad comunal en España, siglos XVIII-XX: una aproximación multicausal y socioambiental a la historia de los montes públicos". Ayer nº42, pp. 191-211.

MARX, Karl.

1983 [1867]: $\quad$ En Defensa de la Libertad. Los artículos de la Gaceta Renana 1842-1843. Edición a cargo de Juan Luis Vernal, Fernando Torres, Valencia.1974 [1867] Capital. A Critical Analysis of Capitalist Production. London: Lawrence \& Wishart.

MONTESINOS, Lidia.

2008 Albor vasco: estudio de una comunidad vascófona en Navarra, lengua e identidad. Terradas i Saborit, I. (director). Treball de recerca de segon any presentat en el programa de Doctorat en Antropología Social i Cultural de la Universitat de Barcelona [texto inédito]

2011 "Helechales Conflictivos. Procesos de Transformación de la Responsabilidad sobre los bienes comunales en Navarra." en Ignasi Terradas (Ed.) Antropología de la Responsabilidad. Santiago de Compostela: Andavira, pp. 191-251.

2013 IRALIKU'K: La confrontación de los comunales. Etnografía e historia de las relaciones de propiedad en Goizueta. Tesis doctoral. Departament d'Antropologia Cultural i Història d'Amèrica i Àfrica. Universitat de Barcelona. http://hdl.handle. net/10803/132603

MOORE, Sally Falk.

1973 Law as a Process. Londres: Routledge \& Kegan Paul.

POLANYI, Karl.

2009 [1977] El sustento del hombre. Madrid: Capitán Swing Libros.

2011 [1957] La gran transformación. Los orígenes políticos y económicos de nuestro tiempo. Buenos Aires: Fondo de Cultura Económica.

PROUDHON, Pierre Joseph.

1983 [1840] ¿Qué es la propiedad?. Barcelona: Orbis.

SERNA VALLEJO, Margarita.

2011 "Apuntes para una revisión del concepto de propiedad liberal en España doscientos años después de Cádiz." en Anuario de Historia del Derecho Español no LXXXI, pp. 469-492.

SIERRA, María Teresa; CHENAUT, Victoria.

2002 "Los debates recientes y actuales en la antropología jurídica: las corrientes anglosajonas" en Esteban Krotz (Ed.) (2002).

SOUSA SANTOS, Boaventura.

1987 “Law a Map of Misreading: Towards a Posmodern Conception of Law" Journal of Law and Society, 14, 3, pp. 279-302. 
1995 Towards a New Common Sense: Law, Science and Politics in the Paradigmatic Transition. Nueva York / Londres: Routledge.

SUPIOT, Alain.

2007 Homo Juridicus. Ensayo sobre la función antropológica del derecho. Argentina: Siglo XXI. 